\title{
TRABALHO DE CAMPO COMO INSTRUMENTO DE ENSINO DE GEOGRAFIA FÍSICA: UM RELATO DE EXPERIÊNCIA NA LAGOA SALGADA, REGIÃO NORTE DO ESTADO DO RIO DE JANEIRO
}

\author{
Angélica Moreira Neves ${ }^{(a)}$, Rodrigo Gomes Oliveira ${ }^{(b)}$, Vinícius Santos Lima ${ }^{(\mathrm{c})}$ \\ (a) Licenciando em Geografia pela Faculdade de Filosofia, Ciências e Letras de Macaé, E-mail: \\ angelicaeleticia@yahoo.com.br \\ (b) Licenciando em Geografia pela Faculdade de Filosofia, Ciências e Letras de Macaé, E-mail: \\ rodrigo.gomesoliveira@yahoo.com.br \\ (c) Professor Adjunto da Licenciatura em Geografia da Faculdade de Filosofia, Ciências e Letras de Macaé, E- \\ mail: vinicius_ahriman@ hotmail.com
}

\section{EIXO: GEOGRAFIA FÍSICA: CURRÍCULO, FORMAÇÃO E PRÁTICA DE ENSINO}

\begin{abstract}
Resumo
Este trabalho tem por objetivo o relato de experiência de uma atividade de campo como requisito da disciplina Geologia Geral do curso de licenciatura em Geografia da Faculdade de Filosofia, Ciências e Letras de Macaé, realizado no município de Campos dos Goytacazes na Lagoa Salgada, corpo lêntico hipersalino, construído em processos transgressivos-regressivos na planície costeira do rio Paraíba do Sul, com presença de estromatólitos holocênicos, pertencente ao projeto "caminhos geológicos" do Serviço Geológico do Estado do Rio de Janeiro. A lagoa Salgada (uma laguna hipersalina) ocupa uma área de $16 \mathrm{~km}^{2} \mathrm{e}$ abriga às únicas ocorrências de estromatólitos carbonáticos colunares, domais estratiformes, trombólitos e oncólitos da idade holocênica do Brasil, e provavelmente de toda a América do Sul.
\end{abstract}

Palavras- chave: hipersalina, estromatólitos, cianobactérias, transgressão marinha.

\section{Introdução}

Lagoas são objetos de estudo de diferentes campos do saber, a exemplo da limnologia, oceanografia e da geologia. Segundo Lima et. al. (2014), a ciência geográfica não tem dado a devida atenção aos ambientes lacustres, que em alguns casos, é fonte de abastecimento para cidades. De acordo com os autores, lagoas são "copos", ou condutos geográfico-geomorfológicos para onde vazam águas de uma bacia hidrográfica, mas que não devem ser pensadas somente em função do alcance espacial de seu espelho e profundidade da coluna d'água em cheias de pequeno intervalo de retorno, mas sim das cheias excepcionais. Assim, os gestores do território melhor poderão gerir esses espaços.

A lagoa Salgada está situada em uma planície arenosa formada por cristas praias holocênicas, ao sul da foz do rio Paraíba do Sul. A partir do Rio de Janeiro, a lagoa Salgada é atingida pela rodovia BR101 (Rio de Janeiro-Campos - 280 km) e depois pela rodovia RJ-216 (Campos- Farol de São Tomé $50 \mathrm{~km})($ SRIVASTAVA, 1999). 
Por se tratar de uma lagoa única no Brasil, em função da presença deste tipo de estromatólito, a lagoa

Salgada tornou-se objeto de interesse para a pesquisa, extensão e o ensino. Algumas são as ferramentas que professores utilizam-se para trabalhar junto aos discentes o conteúdo desejado, dentre as quais se pode destacar o trabalho de campo. Trata-se de uma atividade de grande importância para a compreensão e leitura do espaço, possibilitando o estreitamento da relação entre a teoria e a prática. $\mathrm{O}$ alcance de um bom resultado parte de um planejamento criterioso, domínio de conteúdo e da técnica a ser aplicada (TOMITA, 1999).

Sobre isso, Lacoste (1985) indica que a atividade de campo, para transcender a condição de senso comum, deve articular-se à formação teórica, o que se torna indispensável. Daí pensar o espaço geográfico a partir do diálogo estabelecido entre os referenciais teóricos e o aprendizado dos acadêmicos, possibilitando a compreensão dos diferentes ambientes estudados.

A despeito da importância do campo, a reflexão sobre o que será discutido exige um grau mínimo de organização, permitindo que sejam construídas antecipadamente as primeiras interações com as áreas que deverão ser visitadas. Além disso, é de fundamental importância possuir um conhecimento razoável sobre o objeto de estudo (HUERTAS, 2007).

O trabalho de campo se trata de construção contínua de um saber científico que também pode fazer parte da vida do discente. Nesse sentido, alguns critérios são levados em consideração ao pensar a aula de campo como mediadora do conhecimento em Geografia Física (SILVA et al., 2010; GARÇÃO E CAMPOS, 2012), quais sejam:

a) Escolha do local, considerando a acessibilidade (local, transporte, alimentação e hospedagem;

b) Elaboração do projeto de aula de campo que esclareça bem os objetivos e as metodologias a serem utilizadas;

c) Revisão bibliográfica;

d) Preparação de um roteiro detalhado das atividades de campo;

e) Orientação a respeito da análise integrada da paisagem;

f) Estabelecimento de critérios disciplinares, como horários, normas de conduta, cuidados com acidente e saúde.

Neste sentido, este trabalho objetiva relatar uma atividade de campo realizada com estudantes do $2^{\circ}$ período do curso de licenciatura em geografia da Faculdade de Filosofia, Ciências e Letras de Macaé FAFIMA - como requisito parcial da disciplina de Geologia Geral, pela planície quaternária (costeira) do rio Paraíba do Sul no dia 5 de novembro de 2016, entendendo a importância do trabalho de campo 
OS DESAFIOS DA GEOGRAFIA FÍSICA NA FRONTEIRA DO CONHECIMENTO

Instituto de Geociências - Unicamp Campinas - SP

28 de Junho à 02 de Julho de 2017

para o desenvolvimento do saber, para melhor compreensão da paisagem, para a integração aluno/aluno e aluno/professor.

Busca-se fortalecer as prerrogativas de que não há melhor desenvolvimento de aptidões do que a troca de conhecimento, o levantamento das questões e as soluções advindas dessas discussões. Com esse trabalho integraremos o trabalho de campo aos estudos começados em aula, aliando teoria a prática, concluindo assim o conteúdo da disciplina de geologia.

\section{Metodologia}

O trabalho de campo ocorreu no dia 05 de novembro de 2016, com início às 07 h30minh e término às 20h30minh. O grupo saiu de frente da FAFIMA (Faculdade de Ciências e Letras de Macaé) com licenciandos do $2^{\circ}$ período do curso de Licenciatura em Geografia da FAFIMA a caminho da cidade de Campos dos Goytacazes. Ao chegar ao destino o grupo encontrou-se com o professor o Prof. M.Sc. Vinicius Santos Lima, coordenador da disciplina e os professores convidados José Maria Ribeiro Miro (UFF-Campos) e Raquel da Silva Paes (UFF - Campos).

Foram realizadas as devidas apresentações e a exposição de um mapa da região, com ênfase aos locais onde haveria os estudos, para os alunos poderem se localizar e ambientar com o espaço estudado. Os pontos de estudo foram: Canal Campos-Macaé, foz do rio Paraíba do Sul, Lagoa do Açu e Lagoa Salgada. Dentre os instrumentos técnicos utilizados encontram-se mapas temáticos, como geológicos, hidrogeográficos e geomorfológicos, além de uma bússola para noções básicas de orientação cartográfica.

\section{Resultados e Discussões}

A Lagoa Salgada (Figura 1) está localizada no litoral do município de campos dos Goytacazes, no norte do estado do Rio de Janeiro. Recebe este nome devido a grande concentração de sais presentes nela. Segundo Martin et al. (1993), sua formação aconteceu após uma fase de erosão da planície costeira do Rio Paraíba do Sul e a subida do nível do mar entre 3.900 a 3.600 anos, durante o qual as barreiras arenosas deslocaram-se rumo ao continente, nas condições hidrodinâmicas geradas pelas ondas da área ao sul do Cabo de São Tomé.

Devido ao processo de transgressão marinha, fenômeno de regressão do mar, a única forma de entrada de água doce na lagoa é por meio de precipitação, não havendo fluxo de água de rios convergindo para a lagoa. Dessa forma, ao evaporar a água, os sais permanecem armazenados nela. 


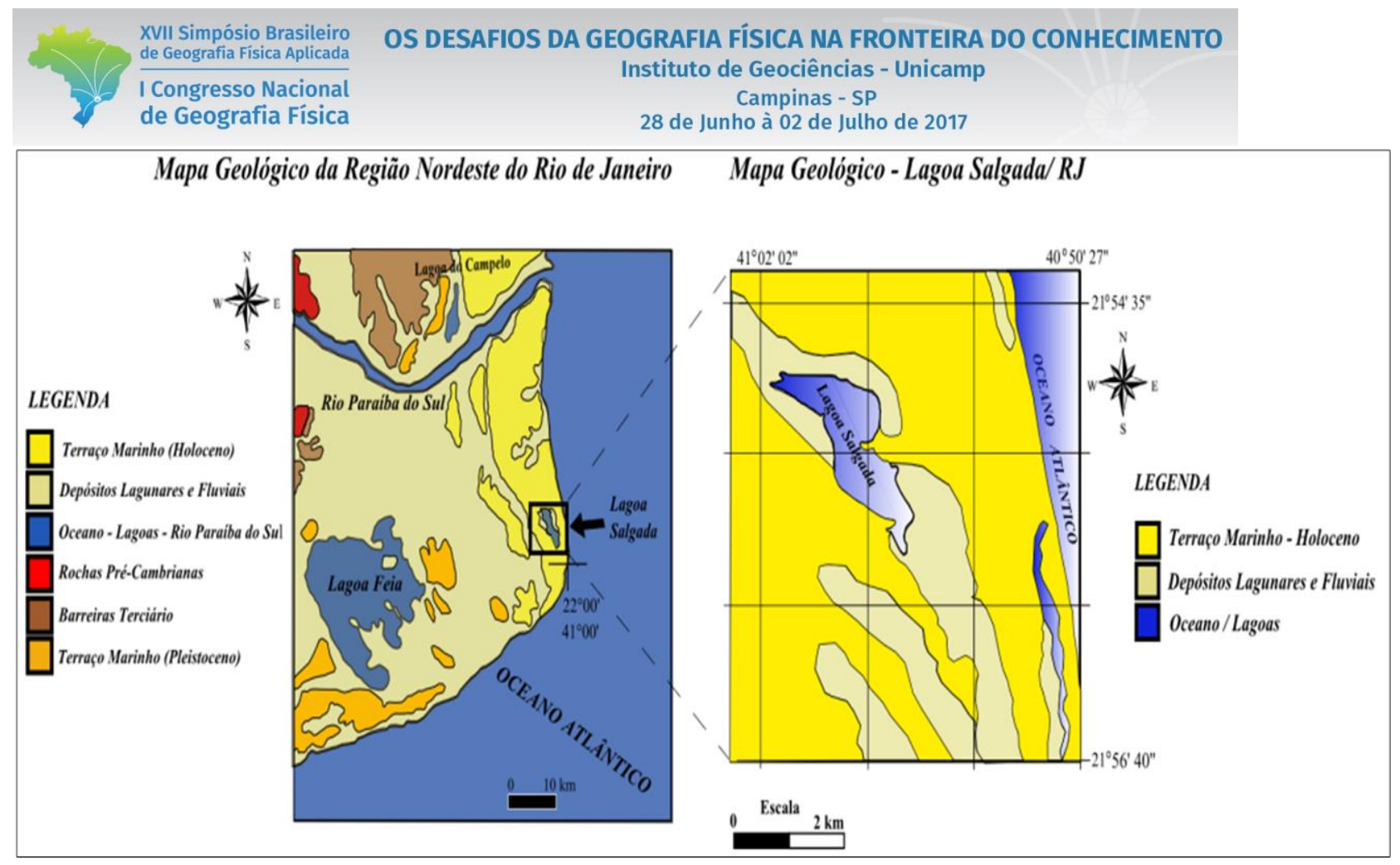

Figura 1 - Mapa da localização da Lagoa Salgada. Fonte: Cataldo (2011).

Srivastaval (1999) indica que moradores relatavam o processo de cheia e estiagem na lagoa Salgada é natural, mas que vem sendo intensificado por ações antropogênicas. Ao redor da lagoa existem flora e fauna da restinga, embora os impactos ambientais provocados pelas atividades humanas tenham devastado quase que completamente estes componentes. 


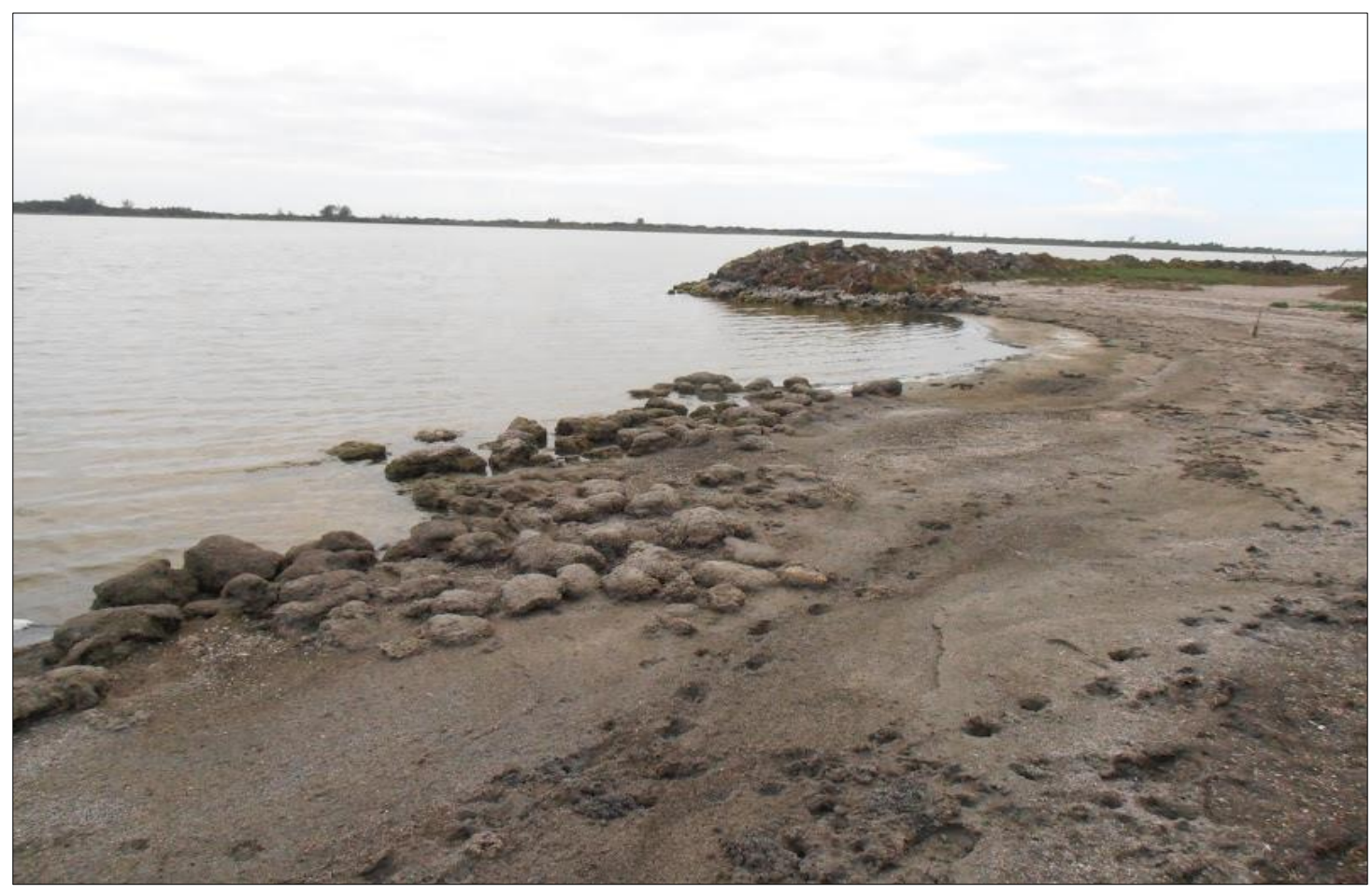

Figura 2 - Lagoa Salgada com água. Fonte: ambientecult. blogspot.com

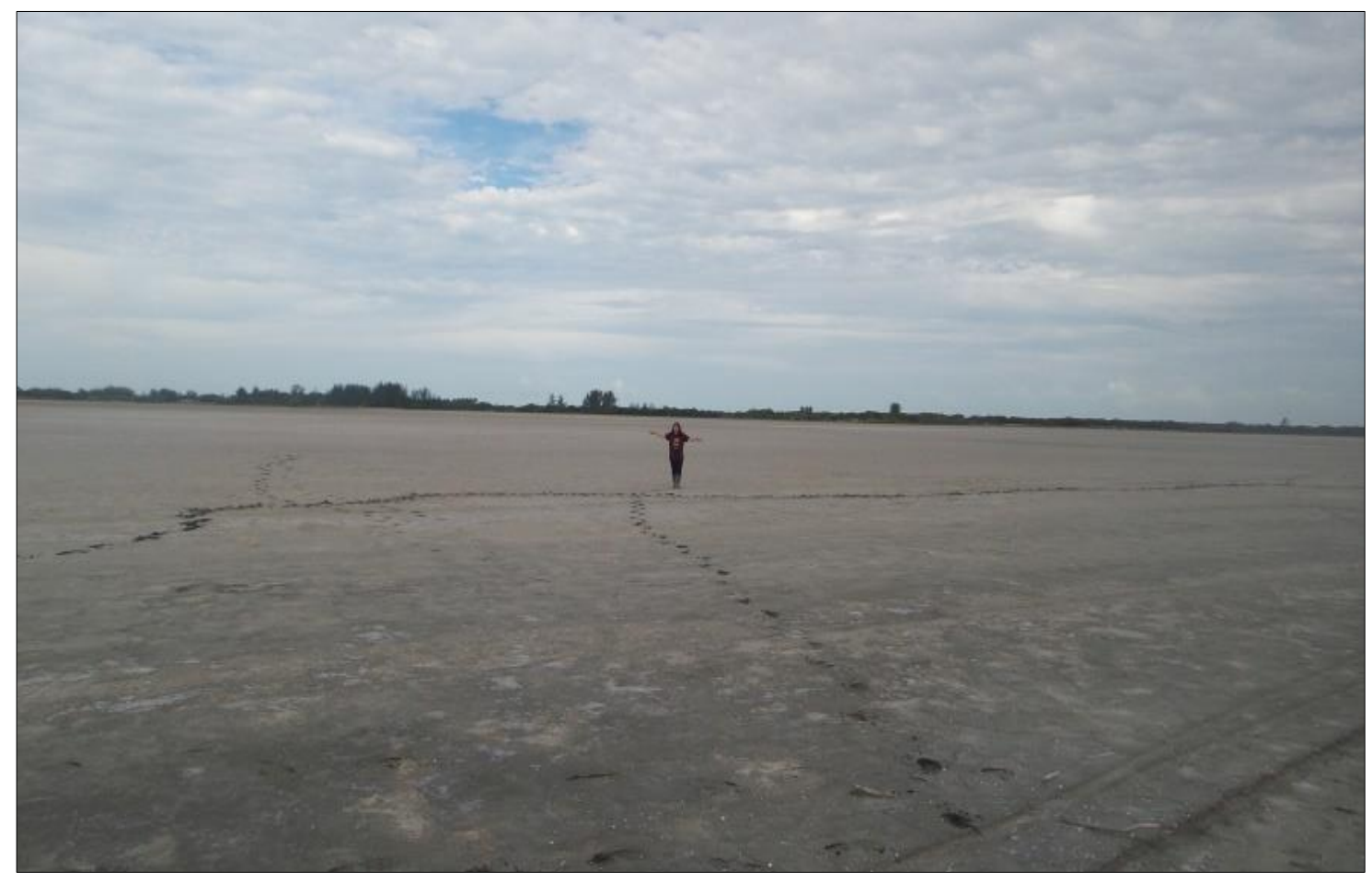

Figura 3 - Lagoa Salgada sem água. Fonte: Dos autores - 05/11/2016. 
Esta é uma lagoa de grande importância geológica, sobretudo para o DRM (Departamento de Recursos Minerais-RJ), devido à presença de estromatólitos. O estromatólito é uma forma oriunda de cianobactérias que se fundiram com carbonatos, aglutinaram- se em camadas, que podem ter duas origens: por precipitação e por aglutinação e na Lagoa Salgada ocorreram os dois tipos.

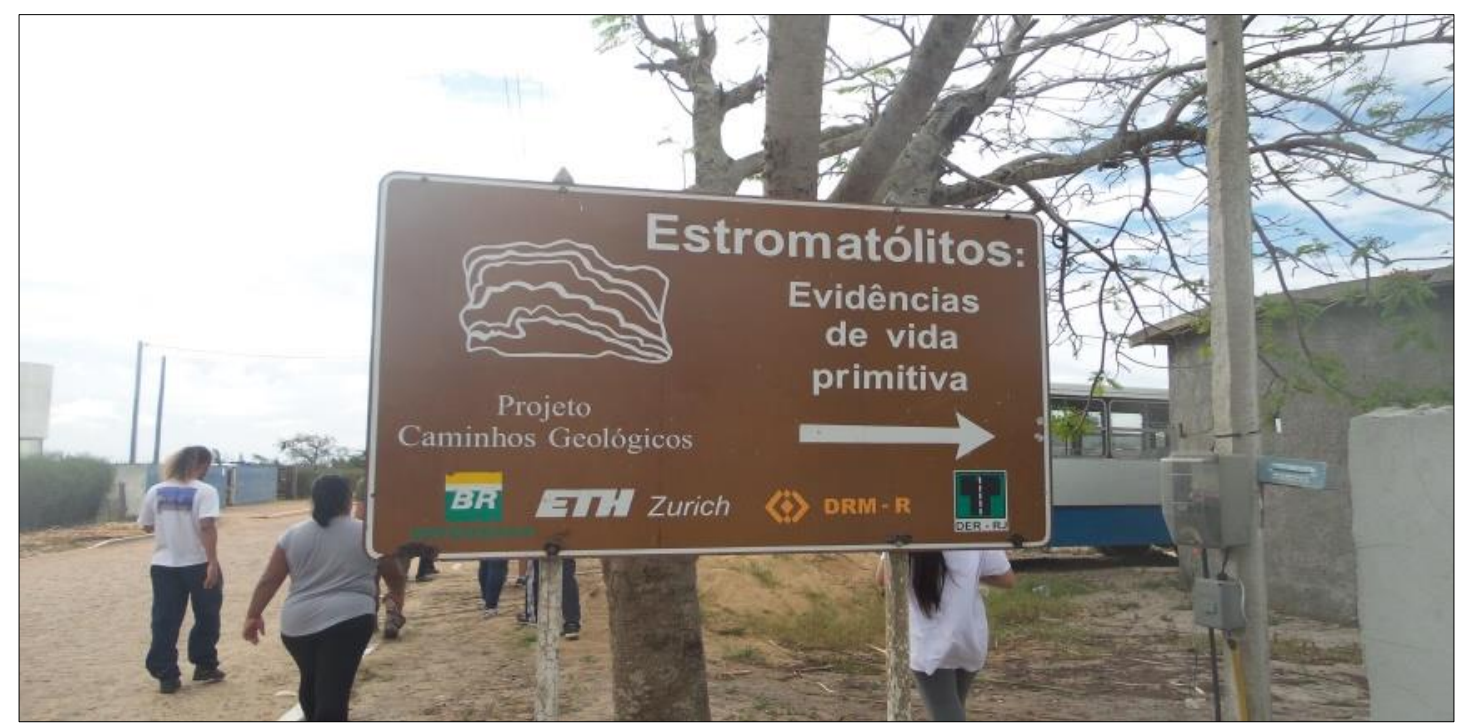

Figura 4 - Placa no acesso a Lagoa Salgada Fonte: Dos autores - 05/11/2016.

Isso é evidencia de vida primitiva na Terra, semelhante às existentes no pré-cambriano. A vida na Terra é datada de 3,5 bilhões de anos antes do presente e os estromatólitos são apresentam condições possíveis de existência desse mesmo período. Existem tipos de estromatólitos, mas como os encontrados na Lagoa Salgada, só existem poucos lugares no planeta, isso devido a sua formação que é por aglutinação e por precipitação. São os estromatólitos estratiformes.

"Nos estromatólitos estratiformes foram encontradas 21 espécies de cianobactérias, Microcoleus chthonoplastes (Thuret) Gomont 1892 e Lyngbya aestuarii (Liebman) Gomont, 1892 se apresentaram frequentes nestes estromatólitos. Nos estromatólitos estratiformes foi observada a presença de calcita. As cianobactérias filamentosas são responsáveis pela união e aprisionamento dos grãos sedimentares, para formar as laminações nestas construções. Restos esqueletais de moluscos, foraminíferos, ostracódios se apresentando na localidade como mais uma fonte de carbonato de cálcio e substrato para estruturar os estromatólitos" (SILVA et al., 2008, p. 46). 


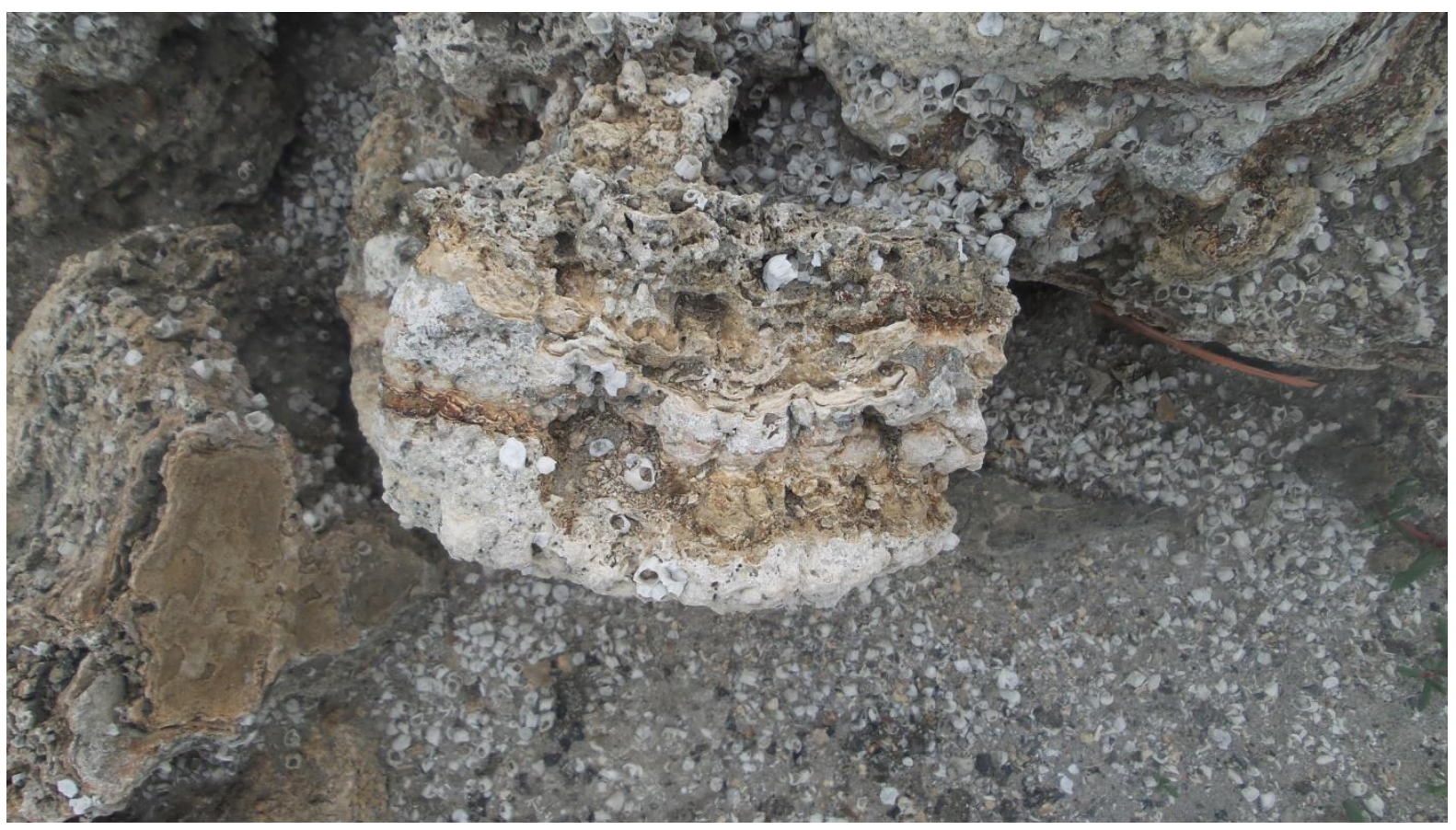

Figura 5 - Estromatólitos Fonte: Dos autores - 05/11/2016.

\section{Conclusão}

O trabalho realizado na lagoa Salgada agregou grande valor à disciplina de geologia geral, dando mais embasamento e sendo bem significativo. Nesta atividade foi possível observar inúmeros conceitos trabalhados em sala de aula, assim como de agregar outros tantos. Às vésperas da aula de campo, a turma já se encontrava bem animada e ansiosa pela pratica, e esta ansiedade e animação foi sendo validada durante o estudo, devido a sua riqueza.

É notável o quão importante é o trabalho de campo no processo ensino-aprendizagem. Esta aprendizagem significativa que leva o discente a relacionar a teoria com a pratica, vendo claramente aquilo que era abstrato e que se torna concreto e, para nós, enquanto professores de geografia torna- se uma necessidade trazer o trabalho de campo para nossa práxis docente.

\section{REFERÊNCIAS}

CATALDO, Rafael Amaral. Análise dos Estromatólitos e sedimentos associados - Lagoa Salgada/RJ (monografia de graduação). Unicampi, Campinas/SP, 2011.

GARÇÃO, Lucimar Marques da Costa; CAMPOS, Alfredo Borges de. Trabalho de campo no ensino de Geografia Física: um relato de experiência no Parque Estadual do Jalapão do Tocantins. In: Temporis (ação), v.11, n. 1, p. 115- 130, jan./dez. 2012.

HUERTAS, Daniel Monterio. Além do aspecto puramente acadêmico: o trabalho de campo como uma verdadeira experiência de vida.P.p. 149 - 156. In: GEOUSP - Espaço e Tempo, São Paulo, No 21, 2007. 
LACOSTE, Ives. A pesquisa e o trabalho de campo: um problema político para os pesquisadores, estudantes e cidadãos. São Paulo, AGB/SP, nº 11, 1-23, agosto de 1985.

LIMA, Vinícius Santos; ALVES, Leidiana Alonso; MIRO, José Maria Ribeiro; COELHO, André Luiz Nascentes. Contribuição à geografia lacustre no Brasil: estudo de caso da lagoa Feia/RJ. In: Revista Geonorte, Edição Especial 4, V.10, N.1, p.245-250, 2014

MARTIN et al. As flutuações de nível do mar durante o quaternário superior e a evolução geológica de deltas brasileiros. In: Boletim IG-USP, Publicação Especial nº15, 186p. 1993.

SILVA, Juliana Ribeiro da; SILVA, Míriam Belarmindoda; VAREJÃO, José Leonídio. Os (dês) caminhos da educação: a importância do trabalho de campo na geografia. Revista VÉRTICES, Campos dos Goytacazes/RJ, v. 12, n. 3, p. 187-197, set./dez. 2010.

SILVA, Loreine Hermida da Silva; IESPA, Anderson Andrade Cavalcanti; IESPA, Cynthia Moreira Damazio. Composição dos Estromatólitos Estratiformes da Lagoa Salgada, Rio de Janeiro, Brasil Composition of the Stratiform Stromatolites of Lagoa Salgada, Rio de Janeiro, Brazil. In: Anuário do Instituto de Geociências UFRJ - Vol. 31 -2 / 2008 p. 42-49.

SRIVASTAVA, N.K. 1999. Estromatólitos Recentes, Lagoa Salgada, RJ. SIGEP 41.

TOMITA, Luzia M. Saito. Trabalho de campo como instrumento de ensino em Geografia. In: Geografia Londrina, v. 8, n. 1, p. 13-15, jan./ jun. 1999. 